\title{
Electrochemical Hydrogen Compression: Efficient Pressurization Concept Derived from an Energetic Evaluation
}

\author{
Michel Suermann, ${ }^{a}$ Thomas Kiupel, ${ }^{a}$ Thomas J. Schmidt, ${ }^{\text {a,b,* }}$ and Felix N. Büchi ${ }^{a, z}$ \\ ${ }^{a}$ Electrochemistry Laboratory, Paul Scherrer Institut, CH-5232 Villigen PSI, Switzerland \\ ${ }^{b}$ Laboratory of Physical Chemistry, ETH Zürich, CH-8093 Zürich, Switzerland
}

\begin{abstract}
Electrochemical hydrogen compression is a potentially high efficient, low-maintenance and silent technology to produce high pressure hydrogen. A new pressure concept with increased compression efficiency, termed intermediate differential pressure polymer electrolyte water electrolysis is proposed. With slightly pressurized oxygen and a much higher hydrogen pressure, this pressure concept profits from the advantages of the lower gas crossover of differential (only hydrogen compressed) pressure water electrolysis and the improved oxygen evolution reaction kinetics with increasing pressure of balanced pressure operation. Data for gas pressures up to $100 \mathrm{MPa}$ is modeled, based on experimental results up to $5 \mathrm{MPa}$, of the three pressure concepts and validated with literature data up to $70 \mathrm{MPa}$. While differential pressure electrolyzer operation, following ideal isothermal compression, can be more efficient than today's best mechanical compressors up to $40 \mathrm{MPa}$, the intermediate pressure concept shows higher compression efficiency up to 90 MPa.

(C) The Author(s) 2017. Published by ECS. This is an open access article distributed under the terms of the Creative Commons Attribution 4.0 License (CC BY, http://creativecommons.org/licenses/by/4.0/), which permits unrestricted reuse of the work in any medium, provided the original work is properly cited. [DOI: 10.1149/2.1361712jes] All rights reserved.

(cc) BY
\end{abstract}

Manuscript submitted June 13, 2017; revised manuscript received August 21, 2017. Published August 30, 2017.

Electricity generation from renewable sources is constantly expanding, e.g. the wind and photovoltaic (PV) power capacity installed in the European Union (EU-28) has increased from $172 \mathrm{GW}$ in 2010 to $236 \mathrm{GW}$ in 2015 and the concurrent electricity generation to about 400 TWh. ${ }^{1,2}$ A major drawback of these technologies is their intermittent generation. Balancing production with consumption in the electric grid becomes a challenge and unused electric energy needs to be curtailed. ${ }^{3}$ At the national level, in 2015, the largest curtailment was required in Germany with 4.7 TWh (127 GWh in 2010) causing estimated costs of $480 \mathrm{M€} .^{4}$

Polymer electrolyte water electrolysis (PEWE), i.e. electrochemical splitting of water into hydrogen and oxygen, is a well suited technology to follow excess power loads and convert it to chemical energy in the form of hydrogen. ${ }^{5}$ With all curtailed energy in Germany in 2015 converted into hydrogen, at $79 \mathrm{kWh} / \mathrm{kg}_{\mathrm{H} 2}$ (compressed to $>70 \mathrm{MPa}$, and precooled for fast filling), ${ }^{6,7}$ the fuel would have been sufficient for about 590,000 fuel cell electric vehicles (FCEVs; $1 \mathrm{~kg}_{\mathrm{H} 2} / 100 \mathrm{~km}$ and $10,000 \mathrm{~km}$ annual driving).

In today's electrolysis plants, hydrogen is produced typically at 3 $\mathrm{MPa}^{8,9}$ and is further compressed mechanically to be fed into the natural gas grid or transported to a hydrogen refueling station (HRS), ${ }^{8,9}$ where the gas is compressed to pressure levels up to $100 \mathrm{MPa}^{10}$ in order to refuel 70 MPa FCEVs.

Conventionally, hydrogen is compressed mechanically using piston compressors. In the best case, this still requires energy of approximately a factor of 1.4 above the thermodynamic requirement, i.e. ideal isothermal compression. ${ }^{11}$ Differential pressure PEWE (only hydrogen is compressed) has been demonstrated up to $70 \mathrm{MPa} .{ }^{12}$ Likewise, electrochemical hydrogen compressors (EHCs), where hydrogen is concentrated and/or compressed from a lower to a higher (partial) pressure, have been demonstrated up to $100 \mathrm{MPa} .^{13}$

In energy related applications, the conversion efficiency is crucial, especially while investment costs for PEWE systems of about $1000-2000 € / \mathrm{kW}^{14,15}$ are still relatively high. In the electrolyzer, the conversion efficiency is reduced by the water splitting reaction overpotentials and losses by gas crossover. An overview on the overpotentials in PEWE is given by Carmo et al., ${ }^{16}$ and on membrane gas permeability by Mittelsteadt and Staser. ${ }^{17}$ The reduced gas drying effort at the plant level, when using pressurized PEWE, is exemplified by Bensmann et al. ${ }^{18}$

In this work we determine the hydrogen compression efficiency considering PEWE cell voltage and gas crossover losses due to pres-

\footnotetext{
*Electrochemical Society Member.
}

${ }^{\mathrm{z} E}$-mail: felix.buechi@psi.ch surization. Conventionally, PEWE is operated with either a differential or balanced (both gases compressed at same pressure) pressure concept. The effect of gas pressure on cell voltage is experimentally analyzed at $1 \mathrm{MPa}$ for the classical PEWE pressure strategies. Based on an energetic evaluation, a novel pressure concept with a slightly increased oxygen pressure and a much higher hydrogen pressure is then introduced as intermediate differential pressure concept and results are shown up to $5 \mathrm{MPa}$. The results from the electrochemical characterization are then combined with the pressure dependent gas crossover losses to calculate the total hydrogen compression efficiency which is extrapolated up to values of $100 \mathrm{MPa}$ and which is discussed for the cases shown in Figure 1, when hydrogen is compressed i) directly using PEWE; ii) with downstream mechanical compression or iii) using EHCs. As also shown, EHCs could be even used to concentrate and/or compress hydrogen from a lower to a higher partial pressure out of a gas mixture, e.g. out of the (natural) gas grid.

\section{Experimental}

Polymer electrolyte water electrolysis test bench and cell.-A small scale electrolysis cell with a square active area of $4 \mathrm{~cm}^{2}$ is used. Commercial catalyst coated membranes (CCMs) with Ir- and Pt-based catalysts (Nafion 117CS and Nafion 212, Greenerity E400, Greenerity, DE) are sandwiched between two $1.0 \mathrm{~mm}$ thick porous transport layers (PTLs) with a porosity of $35 \pm 2 \%$ made from titanium sintered powder (SIKA T10, GKN Sinter Metal Filters, DE). ${ }^{19}$ Gas and water is distributed from and to the PTLs by flow-fields with five parallel channels $(2 \times 1 \mathrm{~mm}$, width $\mathrm{x}$ depth $)$ made from gold-coated stainless steel, to eliminate contact resistances and corrosion issues.

The cell contains a special membrane electrode assembly (MEA) compression mechanism, keeping the contact pressure (here $2.5 \mathrm{MPa}$ ) independent of the clamping pressure needed for the flat gaskets. The test bench consists of two separate gas/water loops with a forced water recirculation at the anode of $30 \mathrm{~mL} \cdot \mathrm{min}^{-1} \cdot \mathrm{cm}^{-2}$, while, at the cathode natural convection takes place. Both PEWE cell and test bench are described in detail in Ref. 20.

PEWE measurement methods.-The overpotentials are characterized with galvanostatic current/voltage characteristics (i/E-curves) from 0.001 to $4 \mathrm{~A} \cdot \mathrm{cm}^{-2}$ with a holding time at each current density of $10 \mathrm{~s}$ plus $1 \mathrm{~s}$ for a high frequency resistance (HFR) measurement. Electric controls are based on a Bio-Logic potentiostat (VSP-300, Bio-Logic SAS, FR). The relatively short holding time is chosen due to safety requirements (gas crossover at low current densities and high pressures) and has been validated in previous work. ${ }^{21}$ The HFR is measured at $25 \mathrm{kHz}$ to correct data for the ohmic overpotential. Before 


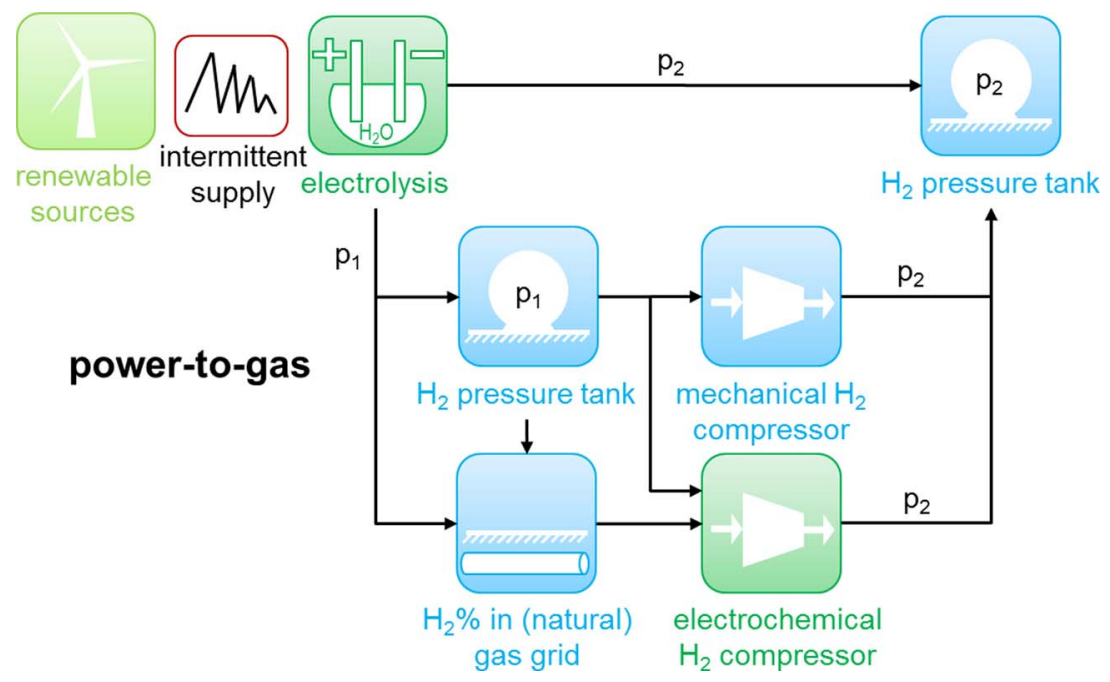

Figure 1. Power-to-gas paths for storing intermittent electric power from renewable sources by conversion into chemical energy via water electrolysis and three different ways of hydrogen transportation, temporary storage (indicated with pressure state $\mathrm{p}_{1}$ ) and compression of hydrogen to the desired pressure state $\mathrm{p}_{2}$. From top to bottom the three different paths are: i) direct compression via PEWE, ii) partial compression via PEWE with downstream temporary storage and mechanical and/or electrochemical compression to $\mathrm{p}_{2}$ and iii) partial compression via PEWE with downstream temporary storage or direct transport via the gas grid and a concentration and compression via $\mathrm{EHC}$ to $\mathrm{p}_{2}$.

measuring $\mathrm{i} / \mathrm{E}$-curves, the cell is operated at a constant current density of $2 \mathrm{~A} \cdot \mathrm{cm}^{-2}$ for at least 10 minutes to achieve thermal equilibrium conditions. The cell temperature is set to $50^{\circ} \mathrm{C}$. However, at higher current densities a temperature gradient of about $1 \mathrm{~K}$ per W/cm ${ }^{2}$ waste heat production leads to a curvature with negative concavity of the reported (iR-free) cell characteristics (i/E-curves), as explained in detail in Ref. 19.

Electrochemical hydrogen compressor experimental setup.The EHC setup is based on a single cell with a rectangular active area of $200 \mathrm{~cm}^{2}(226 \times 88 \mathrm{~mm}$, length $\mathrm{x}$ width). Commercial 7-layer MEAs based on Nafion XL-100 with Pt-based catalysts, microporous layers (MPLs) and gas diffusion layers (GDLs) are used (H500E, Greenerity, DE) which are actually designed for fuel cell applications. The MEA is sandwiched between two flow fields with 50 parallel channels, with a channel depth of $0.3 \mathrm{~mm}$.

EHC measurement methods.-In EHCs hydrogen is oxidized at the anode and then the protons are reduced back to hydrogen with higher partial pressure/compression at the cathode. Two different EHC scenarios are investigated: i) compression of pure hydrogen from a lower to a higher pressure level and ii) concentration and compression of hydrogen from a gas mixture of $5 \% \mathrm{H}_{2}$ in $\mathrm{N}_{2}$ to $100 \% \mathrm{H}_{2}$, representing possible conditions for separating hydrogen from the natural gas grid. Gas is fed in a counter-flow mode to the two MEA sides and humidified to $80 \%$ relative humidity via controlled evaporation and mixing systems (CEMs, Bronkhorst, $\mathrm{CH}$ ). Pure hydrogen is always fed on the cathode side. The cell temperature is $60^{\circ} \mathrm{C}$, controlled by heating/cooling channels inside the plates. A local current density measurement device (Current scan shunt, $\mathrm{S}++$ Simulation Services, DE) with 288 individual segments is implemented.

For the EHC characterization, i/E-curves in the current density range from 0.005 to $2.5 \mathrm{~A} \cdot \mathrm{cm}^{-2}$ with holding times at individual current densities of $40 \mathrm{~s}$ are recorded using a power supply (Agilent Technologies, US). For the $5 \% \mathrm{H}_{2}$ in $\mathrm{N}_{2}$ experiments, the maximum current density is $0.5 \mathrm{~A} \cdot \mathrm{cm}^{-2}$ due to limitations with gas humidification. For both cases the anode (low pressure side) volume flow is equal to 1.5 times the stoichiometric requirement $\left(\lambda_{\mathrm{a}}=1.5\right)$, while the cathode volume flow is equal to $\lambda_{c}=0.5$ for case $i$ ) and $\lambda_{c}=2$ for case ii), based on the anodic consumption of hydrogen. Stoichiometric conditions are reached at current densities greater or equal than $0.5 \mathrm{~A} \cdot \mathrm{cm}^{-2}$ for case i) and $0.1 \mathrm{~A} \cdot \mathrm{cm}^{-2}$ for case ii). Local current densities $(\mathrm{S}++$ unit) are measured simultaneously during $\mathrm{i} / \mathrm{E}$-curves. In the absence of differences across the channels, only the average values and the corresponding standard deviations for each of the 16 columns along the channel are shown in the results. Before measuring $\mathrm{i} / \mathrm{E}$-curves at given parameters, the EHC is conditioned for 15 minutes at $0.25 \mathrm{~A} \cdot \mathrm{cm}^{-2}$. The mean cell voltage and corresponding standard deviation reported are based on at least three measurements.

\section{Theoretical Background}

In this work, two aspects are considered which determine the energetic compression losses due to pressurization. The first is referred to the cell voltage, the second to gas crossover losses. In theory, both losses should increase with pressure. With respect to the cell voltage, from thermodynamics an isothermal compression behavior is expected according to the Nernst equation given in Equation 1:

$$
E_{\text {cell }}^{0}(p, T)=E^{0}(T)+\frac{R \cdot T}{z \cdot F} \ln \left(\frac{\left.a\left(\mathrm{H}_{2}\right) \cdot \sqrt{a\left(\mathrm{O}_{2}\right.}\right)}{a\left(\mathrm{H}_{2} \mathrm{O}\right)}\right)
$$

where $E^{0}(T)$ is the temperature dependent equilibrium potential, ${ }^{22} z$ is the number of electrons exchanged in the electrochemical reaction (2 for hydrogen and 4 for oxygen) and $a$ is the activity of the reactants. For liquid water an activity of unity and for hydrogen and oxygen ideal gas behavior is assumed. ${ }^{23-25}$ Thus the thermodynamic cell voltage decreases with temperature and increases with pressure, e.g. at $50^{\circ} \mathrm{C}$ a voltage increase of $+32 \mathrm{mV}$ per decade of hydrogen pressure (differential) and $+48 \mathrm{mV}$ per decade of both hydrogen and oxygen pressure (balanced) is calculated. For the EHC, Equation 1 simplifies to Equation 2:

$$
E_{\text {cell,EHC }}^{0}(p, T)=\frac{R \cdot T}{2 \cdot F} \ln \left(\frac{a\left(\mathrm{H}_{2, \text { cathode }}\right)}{a\left(\mathrm{H}_{2, \text { anode }}\right)}\right)
$$

The measured cell voltage $E_{\text {cell }}(\mathrm{p}, \mathrm{T})$, i.e. the sum of thermodynamic cell voltage and all overpotentials, increase between pressurized and ambient pressure operation $\Delta E_{\text {cell }}$, normalized to the expected thermodynamic cell voltage, is considered as the electrochemical compression efficiency $\eta_{\mathrm{C}, \mathrm{EC}}$ according to Equation 3:

$$
\eta_{\mathrm{C}, \mathrm{EC}}=\frac{E_{\mathrm{cell}}^{0}(p, T)-\Delta E_{\mathrm{cell}}}{E_{\mathrm{cell}}^{0}(p, T)}
$$

Since the polymer electrolytes suffer from gas crossover by the solution-diffusion mechanism, the faradaic efficiency is less than unity. According to Fick's law, the gas crossover can be expressed as a molar permeation flux $\Phi$ where the driving force is given by the partial pressure difference $\Delta p$ for hydrogen and oxygen, respectively, as shown in Equation 4:

$$
\Phi\left(\mathrm{H}_{2} / \mathrm{O}_{2}\right)=-P\left(\mathrm{H}_{2} / \mathrm{O}_{2}\right) \cdot \frac{\Delta p\left(\mathrm{H}_{2} / \mathrm{O}_{2}\right)}{\delta}
$$

here $P$ is the gas permeability and $\delta$ is the wet thickness of the polymer electrolyte during operation. Both hydrogen and oxygen gas crossover 
losses can be expressed as a gas crossover current density equivalent $j_{x}\left(\mathrm{H}_{2} / \mathrm{O}_{2}\right)$ with the unit $\mathrm{A} \cdot \mathrm{m}^{-2} \cdot \mathrm{Pa}^{-1}$ as formulated in Equation 5:

$$
j_{\mathrm{x}}\left(\mathrm{H}_{2} / \mathrm{O}_{2}\right)=z \cdot F \cdot \frac{P\left(\mathrm{H}_{2} / \mathrm{O}_{2}\right)}{\delta}
$$

Oxygen crossover is important also for the faradaic efficiency of the hydrogen produced, as permeated oxygen reacts chemically at the cathode electrocatalyst to form water, consuming the stoichiometric amount of hydrogen. The faradaic efficiency can be expressed with the ratio of the de facto produced hydrogen gas to the theoretically produced amount as given in Equation 6:

$$
\eta_{\mathrm{F}}=\frac{j-j_{\mathrm{x}}\left(\mathrm{H}_{2}\right)-j_{\mathrm{x}}\left(\mathrm{O}_{2}\right)}{j}
$$

where $j$ is the applied current density. Additional losses due to leakage are vanishingly small and thus neglected. ${ }^{20}$ Finally the electrochemical compression efficiency and the faradaic efficiency are combined to the total compression efficiency as given in Equation 7:

$$
\eta_{\mathrm{C}, \text { total }}=\eta_{\mathrm{C}, \mathrm{EC}} \cdot \eta_{\mathrm{F}}
$$

The total electrochemical compression efficiency is calculated based on the thermodynamic cell voltage, corresponding to the lower heating value (LHV) of hydrogen of $240 \mathrm{~kJ} / \mathrm{mol}$. Because in most energy applications only the hydrogen produced is of interest and oxygen produced is considered as a by-product, all given electrochemical compression efficiencies are calculated based on the thermodynamic cell voltage increase due to hydrogen pressurization only (see Equation 1). If oxygen would be of interest too, the electrochemical compression efficiencies for balanced pressure PEWE would be even higher. Nevertheless, in all cases both oxygen and hydrogen gas crossover are considered for the faradaic efficiency in Equation 6.

When comparing different PEWE operating parameters or materials, ultimately not only the compression work is of interest, but all losses. Consequently the cell voltage is considered in the cell efficiency according to Equation 8:

$$
\eta_{\text {cell,PEWE }}=\frac{E_{\text {cell }}^{0}(p, T)}{E_{\text {cell }}(p, T)} \cdot \eta_{\mathrm{F}}=\frac{E_{\text {cell }}^{0}(p, T)}{E_{\text {cell }}(\text { ambient }, T)} \cdot \eta_{\mathrm{C} \text {,total }}
$$

In this work, the cell efficiency is normalized to $E_{\text {cell }}^{\circ}=\mathrm{f}\left(\mathrm{p}_{\mathrm{H} 2}, \mathrm{~T}\right)$ according to Equation 1. If oxygen would be of interest too, the cell efficiencies for balanced pressure operations would be even higher, because of an increase in the thermodynamic cell voltage with oxygen pressure.

\section{Results}

Electrochemical compression losses in differential and balanced pressure $\boldsymbol{P E W E}$. - Thermodynamics predict an isothermal compression behavior for pressurized electrolysis and EHCs increasing the cell voltage (Equation 1). Experimental results for the cell voltage increases due to pressurization are discussed in the form of the electrochemical compression efficiency (Equation 3).

In all experiments the high frequency resistance (HFR) is measured at $25 \mathrm{kHz}$. Only negligible changes are observed for the HFR with pressure $\left( \pm 0.01 \mathrm{Ohm} \cdot \mathrm{cm}^{2}\right.$ at $\left.2 \mathrm{~A} \cdot \mathrm{cm}^{-2}\right),{ }^{20}$ and therefore the ohmic overpotential is considered as not relevant for the evaluation of pressurization losses and thus all data is iR-corrected. In Figure $2 \mathrm{~A} \mathrm{i} /$ E-curves at $50^{\circ} \mathrm{C}$ for ambient $(0.1 \mathrm{MPa})$, and $1 \mathrm{MPa}$ balanced and differential pressure operation are reported. When the data is analyzed for the pressure induced cell voltage increase for the differential $1 \mathrm{MPa}$ operation, as expected, a behavior close to isothermal compression is observed. For balanced pressure operation however, the cell voltage coincides only at low current densities $\left(<0.5 \mathrm{~A} \cdot \mathrm{cm}^{-2}\right)$ with the differential pressure curve, at higher current densities ( $>$ ca. $3 \mathrm{~A} \cdot \mathrm{cm}^{-2}$ ) it approaches the cell voltage values for ambient pressure operation. Consequently, with oxygen compression beneficial processes take place, reducing the apparent compression effort. These effects have been referred to improved oxygen evolution reaction
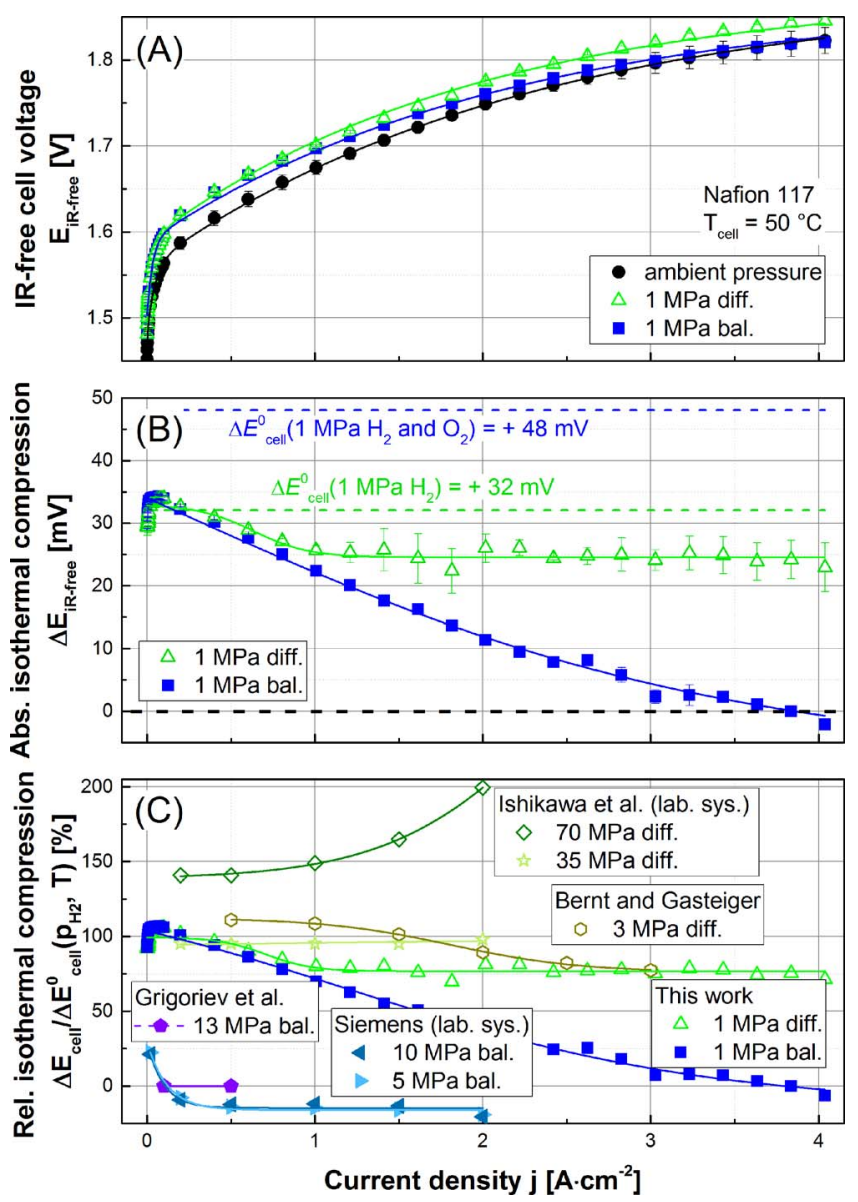

Figure 2. Effect of pressure strategy in PEWE on compression efficiency: (A) iR-free i/E-curves for $0.1 \mathrm{MPa}$ (ambient), $1 \mathrm{MPa}$ differential and balanced pressure PEWE at $50^{\circ} \mathrm{C}$; (B) Absolute differences between the pressurized and ambient pressure cell voltages, and expected thermodynamic cell voltage increases at $50^{\circ} \mathrm{C} ;(\mathrm{C})$ ratio of cell voltage differences between pressurized and ambient pressure operation $\left(\Delta E_{\text {cell }}\right)$ and the theoretical thermodynamic cell voltage increase $\left(\Delta E^{\circ}\right.$ cell $\left.\left(\mathrm{p}_{\mathrm{H} 2}, \mathrm{~T}\right)\right)$ considering only hydrogen compression, i.e. $100 \%$ represents an isothermal compression behavior according to Equation 1.

(OER) kinetics, i.e. an increased apparent exchange current density with pressure. ${ }^{21,26}$

The different behavior of differential and balanced pressure on the pressure induced voltage increase is more closely analyzed by plotting the cell voltage difference between the 1.0 and $0.1 \mathrm{MPa}$ data versus the current density in Figure 2B. The theoretical cell voltage increase at $50^{\circ} \mathrm{C}$ is $32 \mathrm{mV}$ per decade of hydrogen pressure and $48 \mathrm{mV}$ per decade of both hydrogen and oxygen pressure increase. For the differential pressure operation, an isothermal compression behavior of about $80 \%$ of the theoretical value is observed for current densities above $1 \mathrm{~A} \cdot \mathrm{cm}^{-2}$. This means that the compression via differential pressure mode is slightly less, but close to ideal isothermal compression. In contrast, for the balanced pressure operation, the compression induced cell voltage increase drops with increasing current density and at a current density of $3.6 \mathrm{~A} \cdot \mathrm{cm}^{-2}$ no voltage increase at all is observed. At this current density the improvements in OER kinetics fully compensate the pressure induced cell voltage increase expected for an ideal isothermal compression according to Equation 1.

A detailed analysis of previously reported data in the literature for the differential and balanced pressure strategies shows that the present experimental data are in good agreement with literature as summarized in Table I. Literature values are extracted from the published graphs.

The observations of the relative compression losses from this study and the above literature data, are compared in Figure $2 \mathrm{C}$, where the 
Table I. Literature overview of balanced and differential pressure PEWE compression behavior.

\begin{tabular}{llll} 
Pressure mode & Reference & Operating pressure [MPa] & Isothermal compression behavior [\%] \\
\hline differential & Ayers et al. ${ }^{27}$ & $1.4,7.6$ and 16.6 & $\approx 100 \pm 30$ \\
& Bernt and Gasteiger ${ }^{28}$ & 0.1 to 3 & $\approx 80-110$ \\
& Ishikawa et al. ${ }^{12}$ & $0.1,35$ and 70 & $35 \mathrm{MPa}: \approx 100$, \\
& & $70 \mathrm{MPa}: \approx 150$ \\
& & & $\approx 80-95$ \\
Suermann et al. ${ }^{20}$ & $0.1,1$ and 5 & $\geq 0.7 \mathrm{~A} \cdot \mathrm{cm}^{-2}:<0$ \\
balanced & Grigoriev et al. ${ }^{26}$ & 0.1 and 2.5 & $\approx 0$ \\
& Grigoriev et al. $^{29}$ & 0.1 to 13 & $\geq 0.7 \mathrm{~A} \cdot \mathrm{cm}^{-2}: \approx-20$ \\
& Siemens ${ }^{30}$ & $0.1,1$ and 10 & $\geq 1.5 \mathrm{~A} \cdot \mathrm{cm}^{-2}: \approx 0$
\end{tabular}

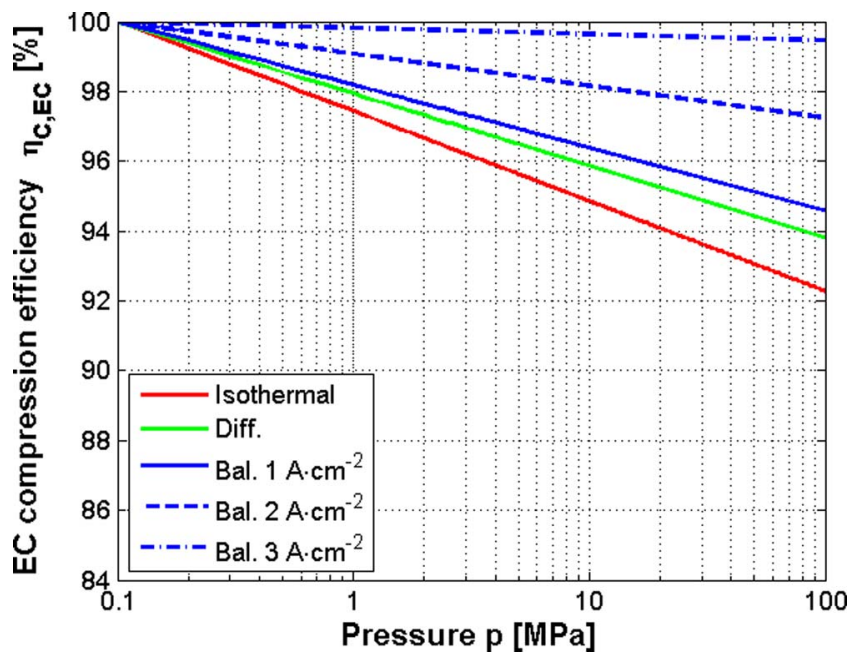

Figure 3. Electrochemical compression (EC) efficiency for differential and balanced pressure PEWE at $50^{\circ} \mathrm{C}$ as a function of the operating pressure. Data are based on experimental results up to $1 \mathrm{MPa}$ from Figure 2B. Isothermal compression is calculated according to Equation 1. No gas crossover losses are considered here.

cell voltage differences between pressurized and ambient pressure are normalized to the corresponding thermodynamic cell voltage increase (again only hydrogen is of interest and oxygen is considered as a byproduct). For differential pressure operation a compression behavior close to the isothermal values are observed up to $35 \mathrm{MPa}$. The $70 \mathrm{MPa}$ differential pressure data from Ishikawa et al. ${ }^{12}$ shows a significantly higher apparent compression effort of about $150 \%$, which might be explained with an increased non-ideal gas behavior, i.e. a hydrogen compressibility factor of approximately $1.4\left(60^{\circ} \mathrm{C}, 70 \mathrm{MPa}\right){ }^{31}$ The balanced pressure operation data at 1.0 and $10 \mathrm{MPa}$ of Siemens ${ }^{30}$ as well as the results of Grigoriev et al. ${ }^{26,29}$ show a higher effect of the improved OER kinetics than this study with negative apparent compression effort of up to $-20 \%$.

Summarizing, the results of this study are qualitatively in line with literature up to $35 \mathrm{MPa}$ differential pressure. When extrapolating these results to higher pressures, the compression work required is underestimated for the differential pressure case. In contrast, for the balanced pressure our experimental results are less optimistic than literature, so when extrapolating our data to higher pressures, the compression losses are rather overestimated. Therefore the comparison between differential and balanced pressure based on the present experimental data, when extrapolating to higher pressures, will produce conservative estimates.

The electrochemical compression efficiencies extrapolated up to $100 \mathrm{MPa}$ are shown in Figure 3. The losses for the differential pressure are based on $80 \%$ isothermal compression behavior and independent of the current density. For balanced pressure, however, the electrochemical compression efficiency increases with current density and curves are shown for 1,2 and $3 \mathrm{~A} \cdot \mathrm{cm}^{-2}$. At $3 \mathrm{~A} \cdot \mathrm{cm}^{-2}$ an electrochemical compression efficiency at $100 \mathrm{MPa}$ of $99 \%$ is calculated.

Electrochemical hydrogen compressor.-Electrochemical hydrogen compressors (EHCs) concentrate and/or compress hydrogen from anode to cathode. In this study two different scenarios are investigated: i) compression of pure hydrogen and ii) extraction and compression of hydrogen out of the natural gas grid. For both scenarios hydrogen is compressed from 0.1 to $0.2 \mathrm{MPa}$ absolute pressure, for case i) pure hydrogen is supplied and in case ii) a gas mixture with $5 \% \mathrm{H}_{2}$ in $\mathrm{N}_{2}$, in order to simulate the dilution in the natural gas grid where the $5 \%$ are considered an upper limit with respect to today's regulations. ${ }^{32}$ Thus compression ratios of 2 and 40 are realized in scenarios i) and ii), respectively.

The two EHC scenarios are compared in Figure 4A. When extrapolating the cell voltage from the stoichiometric range, i.e. above 0.5 $\mathrm{A} \cdot \mathrm{cm}^{-2}$ for case i) and above $0.1 \mathrm{~A} \cdot \mathrm{cm}^{-2}$ for case ii), to equilibrium conditions, offsets of about $5.0 \pm 1.4 \mathrm{mV}$ for case i) and 58.6 $\pm 0.5 \mathrm{mV}$ for case ii) can be extracted which are close to the calculated theoretical values ( 10 and $53 \mathrm{mV}$, based on Equation 2 without considering any water vapor and hydrogen consumption along the channel). Hence, for hydrogen concentration and compression using $\mathrm{EHC}$, an isothermal compression behavior, close to the theoretical values, is observed, similar to the results described for differential pressure PEWE (see Figure 3).

The slopes of the i/E-curves for cases i) and ii) in Figure $4 \mathrm{~A}$ are significantly different. In the absence of kinetic overpotential contributions due to the highly reversible hydrogen oxidation and evolution reactions (HOR and HER), ${ }^{33}$ the slope represents the area specific resistance. For the case of pure hydrogen a value of $95 \mathrm{~m} \Omega \cdot \mathrm{cm}^{2}$ and for the diluted hydrogen $149 \mathrm{~m} \Omega \cdot \mathrm{cm}^{2}$ are observed. The pure hydrogen case is in good agreement with literature results of Shi et al., ${ }^{34}$ who reported a through-plane area specific resistance for the same type of membrane, with a thickness of about $33 \mu \mathrm{m}$, in the order of $80-90$ $\mathrm{m} \Omega \cdot \mathrm{cm}^{2}\left(70^{\circ} \mathrm{C}, \mathrm{rh}=80 \%\right.$, based on ex-situ HFR measurements). The deviation observed for case ii) may originate from the uneven current density distribution between the anode inlet to outlet as outlined in Figure 4B. The uneven current density distribution is attributed to an insufficient membrane humidification, especially at the anode outlet. This hypothesis was underlined with additional experiments injecting liquid water into the cathode $\left(\mathrm{rh}_{\mathrm{c}} \geq 100 \%\right)$ resulting in temporarily decreased area specific resistances in the order of 90 to $100 \mathrm{~m} \Omega \cdot \mathrm{cm}^{2}$, similar to case i), and in more homogenous current density distributions as shown in Figure 4B. However, having partly liquid water in the cathode, no steady-state conditions were obtained with the current setup used. A further possibility is the appearance of transport losses at the anode outlet. Here two-thirds of the diluted hydrogen has been consumed and the hydrogen content in nitrogen drops to $1.7 \%$ eventually giving rise to anodic transport overpotential.

For EHCs in technical applications, the humidification concept is a key challenge, in particular when hydrogen is concentrated and/or compressed out of a dry gas mixture, e.g. out of a natural gas pipeline. The water management in EHCs, which is strongly influenced by the electro-osmotic water drag from anode to cathode, is also reflected in 

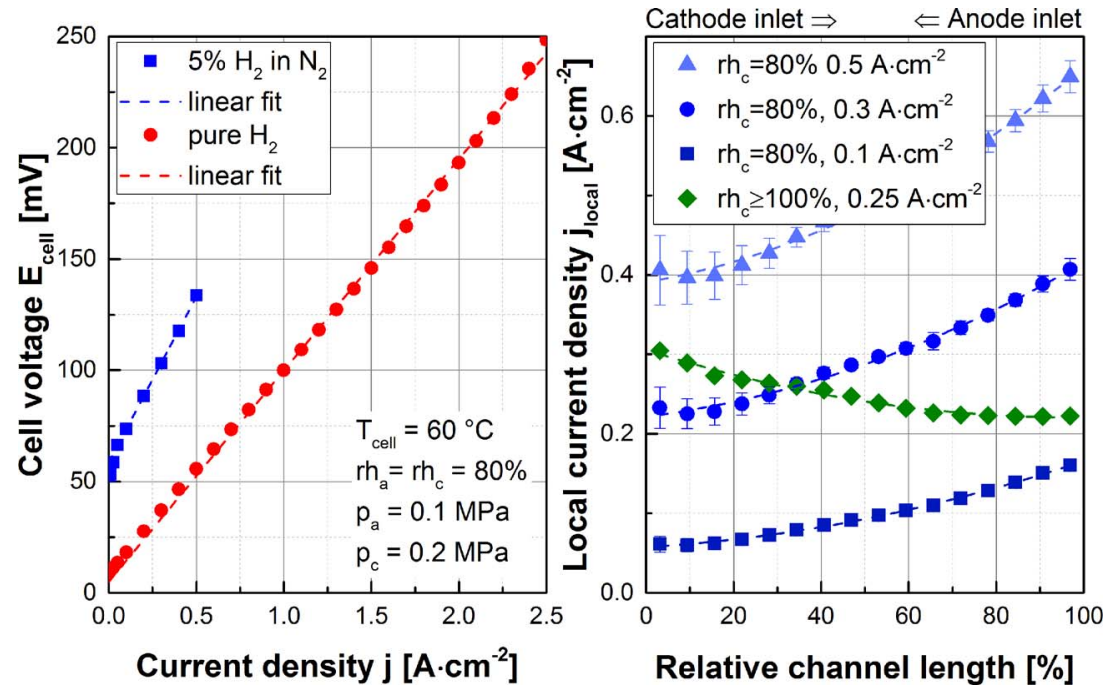

Figure 4. (A) EHC i/E-curves at $60^{\circ} \mathrm{C}$ using Nafion $\mathrm{XL}$ 100 membrane for compressing hydrogen from 0.1 to 0.2 MPa (cell pressures) for case i) pure hydrogen (red circles) and case ii) $5 \%$ hydrogen in nitrogen (blue squares); the relative humidity of all gases is $80 \%$; lines show linear fits of the cell voltage above $0.5 \mathrm{~A} \cdot \mathrm{cm}^{-2}$ for case i) and above 0.1 $\mathrm{A} \cdot \mathrm{cm}^{-2}$ for case ii), extrapolated to equilibrium conditions at $0 \mathrm{~A} \cdot \mathrm{cm}^{-2}$. Linear fit and $\mathrm{y}$-axis intercept for case i) are $95 \mathrm{~m} \Omega \cdot \mathrm{cm}^{2}$ and $5 \mathrm{mV}$, for case ii) $149 \mathrm{~m} \Omega \cdot \mathrm{cm}^{2}$ and $59 \mathrm{mV}$. (B) EHC local current density distribution at $60^{\circ} \mathrm{C}$ at mean current densities indicated. The $\mathrm{rh}_{\mathrm{c}}=80 \%$ data corresponds to the $5 \% \mathrm{H}_{2}$ in $\mathrm{N}_{2} \mathrm{i} / \mathrm{E}$-curve shown in (A). For the counterflow arrangement the cathode inlet is at length 0 and the anode inlet at length $100 \%$. the work of Grigoriev et al. ${ }^{35}$ using less diluted hydrogen in nitrogen gas mixtures. The authors observed a turning point in the $\mathrm{EHC} \mathrm{i} / \mathrm{E}$ data with diluted anode gas at relatively low current densities of only 0.2 to $0.3 \mathrm{~A} \cdot \mathrm{cm}^{-2}$, which was attributed to an insufficient humidification of the Nafion 117 membranes used. ${ }^{35}$ Nevertheless, compression ratios up to 130 were realized confirming the largely isothermal compression behavior of the EHC. ${ }^{35}$ In summary, the experimental findings confirm an isothermal compression behavior of EHCs, which is also in line with earlier literature data. ${ }^{13,36,37}$ From the energetic point of view, the compression behavior of EHCs and differential pressure PEWE are similar, therefore for energy considerations only differential and balanced pressure PEWE are compared below. However from the safety point of view, EHC's may have advantages at high pressures, as no pure oxygen is present in the vicinity of high pressure hydrogen. Also from the application point of view, EHC's may be used when the hydrogen is stored at an intermediate pressure and/or transported from the electrolyzer to its final destination (Figure 1).

Faradaic losses due to gas crossover-In addition to the above discussed electrochemical compression losses, faradaic losses occur due to gas crossover through the polymer electrolyte. Assuming that pressure dependence of the gas permeability of Nafion membranes can be described by a pure solution-diffusion process, as experimentally demonstrated up to $22 \mathrm{MPa}$ differential pressure by Barbir, ${ }^{38}$ data from Schalenbach et al. ${ }^{39}$ are used, which have been validated for 10 MPa balanced pressure earlier. ${ }^{20}$ Recent research has questioned this assumption for electrolyzers, it was postulated that the current indirectly influences the gas crossover, especially for conditions close to ambient pressure, due to increased partial pressures in the catalyst layers with increasing current density. ${ }^{40}$ The fact that oxygen permeability is about half that of hydrogen has consistently also measured by Sakai et al. ${ }^{41}$

Considering that the thickness of water swollen membranes during operation is larger than their nominal thickness $(209,152$ and $63 \mu \mathrm{m}$ for the nominally dry 175,125 and $50 \mu \mathrm{m}$ i.e. in the often used imperial units the 7,5 and 2 mil membranes), ${ }^{39}$ the gas crossover current density equivalent $j_{\mathrm{x}}\left(\mathrm{H}_{2} / \mathrm{O}_{2}\right)$ is calculated according to Equation 5 and given in Figure 5A. Its apparent linear behavior with temperature is visualized using linear fits, allowing for interpolating for different temperatures. Even though the permeability of oxygen is only about half that of hydrogen, the corresponding gas crossover currents are similar to hydrogen, because the current equivalent of oxygen is twice that of hydrogen when permeated oxygen reacts at the cathodic catalyst to form water. Unreinforced, thin membranes are discussed here to illustrate the influence of membrane thickness on gas permeation and overall cell efficiency. For long term field applications however more advanced materials will be needed. ${ }^{17,42}$
From the gas crossover data, the faradaic efficiency is calculated for different membrane thicknesses and current densities (Equation 6) as a function of the operating pressure and given in Figure $5 \mathrm{~B}$ for the differential pressure at $50^{\circ} \mathrm{C}$. For EHCs similar gas crossover losses are obtained, but for balanced pressure operation the gas crossover losses are roughly twice as large. Furthermore, estimates for (hypothetic) new membrane materials with different fractions of the Nafion gas permeability $(0.5,0.2$ and 0.1$)$ are added. For the $1 / 10$ Nafion 112 membrane the faradaic efficiency at $100 \mathrm{MPa}$ increases to above $96 \%$ from less than $70 \%$ for the standard material (Figure 5B). Improvements in the membrane permeability seem to be possible by reinforcing the membrane ${ }^{27}$ or by replacing the perfluoroalkylsulfonic acid based membranes with different chemistry, e.g. hydrocarbons. ${ }^{17}$

Total hydrogen compression efficiency.-In order to predict the total hydrogen compression efficiency, both electrochemical compression and faradaic efficiency need to be combined, as given in Equation 7. As discussed above, because only hydrogen is of interest as a product, both pressure strategies are compared to the thermodynamic cell voltage increase of $+32 \mathrm{mV}$ per decade of hydrogen pressure $\left(\right.$ at $\left.50^{\circ} \mathrm{C}\right)$. However, both hydrogen and oxygen (recombining at the cathode to water) crossover losses are included in the calculations.

The results for Nafion 117 for differential and balanced pressure for the electrochemical compression efficiency (Figure 3) and the corresponding faradaic efficiency (Figure 5B) are combined and the results are given in Figure 6. With respect to the resulting total compression efficiency several general statements can be formulated:

- At low operating pressures the total compression efficiency is dominated by isothermal compression behavior (linear curve shape in the semi-logarithmic plots).

- With increasing operating pressure the losses due to gas crossover become more dominant and curve shapes change from linear to exponential.

- Differential pressure PEWE has better total compression efficiency at low current densities (up to about $1 \mathrm{~A} \cdot \mathrm{cm}^{-2}$ ) because of similar electrochemical compression behavior, but lower oxygen permeation losses compared to balanced operation.

- Balanced pressure strategy has lower apparent compression losses at high current densities (here $3 \mathrm{~A} \cdot \mathrm{cm}^{-2}$ ) up to about $10 \mathrm{MPa}$ using Nafion 112 or up to $50 \mathrm{MPa}$ using Nafion 117, because the oxygen crossover losses are offset by the OER kinetic gains.

- From an energetic point of view, electrochemical compression is more efficient, especially at the high current density, up to $10 \mathrm{MPa}$ for Nafion 112 or $50 \mathrm{MPa}$ using Nafion 117 than the (probably) best mechanical 5-stage ionic liquid hydrogen compressors ${ }^{11}$ (having a loss factor of about 1.4 times the thermodynamic requirement). 

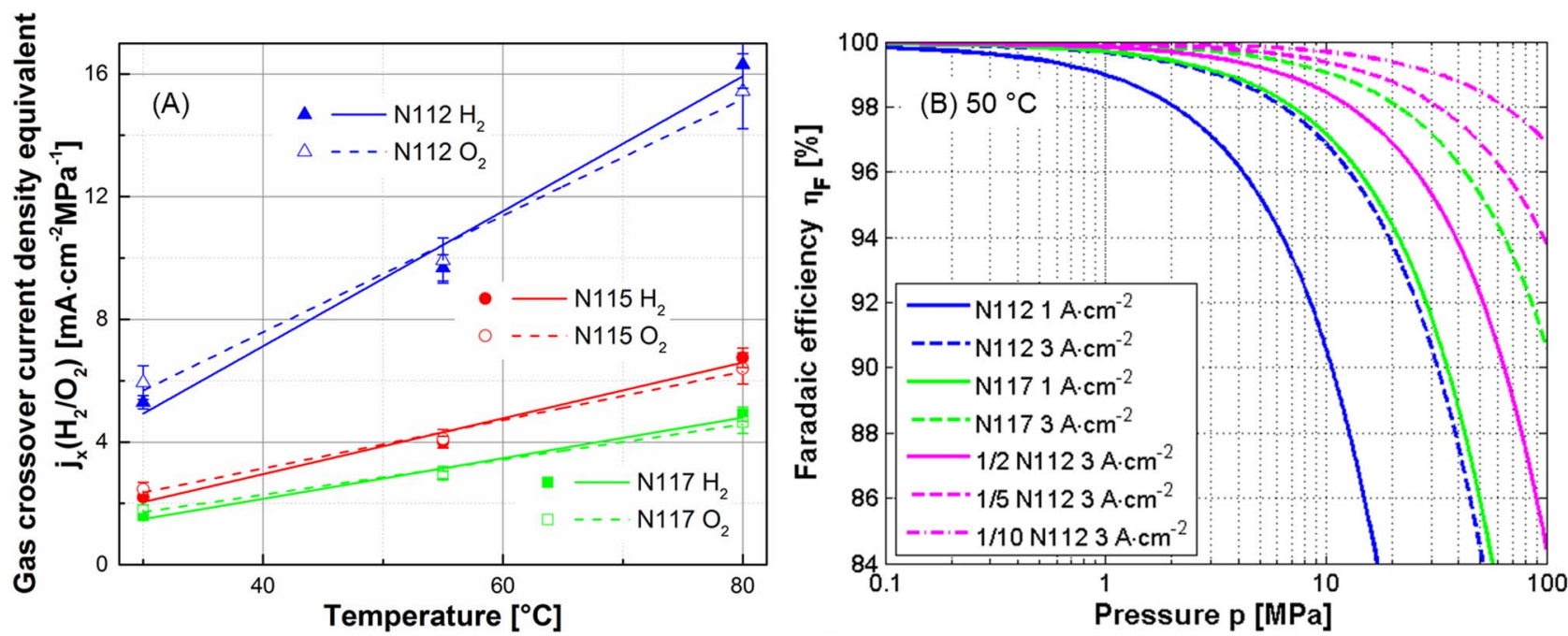

Figure 5. (A) Hydrogen and oxygen gas crossover current density equivalents for wet 7, 5 and 2 mil thick Nafion membranes (actual thickness 209,152 and $63 \mu \mathrm{m}$ ). Linear fits are added for both hydrogen (solid lines) and oxygen (dashed lines); Data is calculated based on the experimental results of Schalenbach et al. ${ }^{39}$ (B) The corresponding faradaic efficiency is calculated for differential pressure PEWE using wet Nafion 117 or Nafion 112 at 1 and $3 \mathrm{~A} \cdot \mathrm{cm}^{-2}$ for $50^{\circ} \mathrm{C}$ as a function of the operating pressure. The data is based on Figure 5A. Hypothetic new membranes with the thickness of Nafion 112 and different fractions of the permeability $(0.5,0.2,0.1)$ are added for discussion.

- Hypothetic new membranes with a permeability of only one tenth of Nafion dramatically reduce the gas crossover losses enhancing compression efficiency; with such a membrane material $93 \%$ compression efficiency would be obtained for a 2-mil membrane at 100 $\mathrm{MPa}\left(3 \mathrm{~A} \cdot \mathrm{cm}^{-2}\right.$ and balanced pressure). This is similar to isothermal compression behavior and would outperform today's best mechanical compressors.

Considering the total cell efficiency, membrane thickness does not only influence the gas crossover losses, but also the corresponding ohmic overpotential. Thus, a tradeoff between both losses has to be found for the optimal cell efficiency, as discussed below.

$\boldsymbol{P E W E}$ cell efficiency. - The main focus is on the hydrogen compression efficiency. However, when discussing the gas permeability properties of different membrane types or thicknesses, it should also be paid attention on the cell efficiency considering the faradaic losses, electrochemical compression losses and all other overpotentials including the (ionic) ohmic resistances of the membrane. Hence, depending on the desired hydrogen pressure, a tradeoff between the membrane induced ohmic overpotential and gas crossover needs to be found. Therefore the total compression efficiency data in Figure 6 are combined with measured PEWE cell performance (according to Equation 8) using Nafion 112 and 117 membranes at $50^{\circ} \mathrm{C}$ and ambient pressure and results shown in Figure 7. The given cell efficiencies are based on the LHV of hydrogen. The corresponding cell voltages at 1 and $3 \mathrm{~A} \cdot \mathrm{cm}^{-2}$ are 1.85 and $2.11 \mathrm{~V}$ for Nafion 112 and 1.97 and 2.50 $\mathrm{V}$ for Nafion 117, respectively. Similar i/E-curves at $1 \mathrm{MPa}$ balanced pressure are given in Ref. 21.

The observations concerning the hydrogen compression efficiency (Figure 6) are still valid, thus only few new insights are deduced:
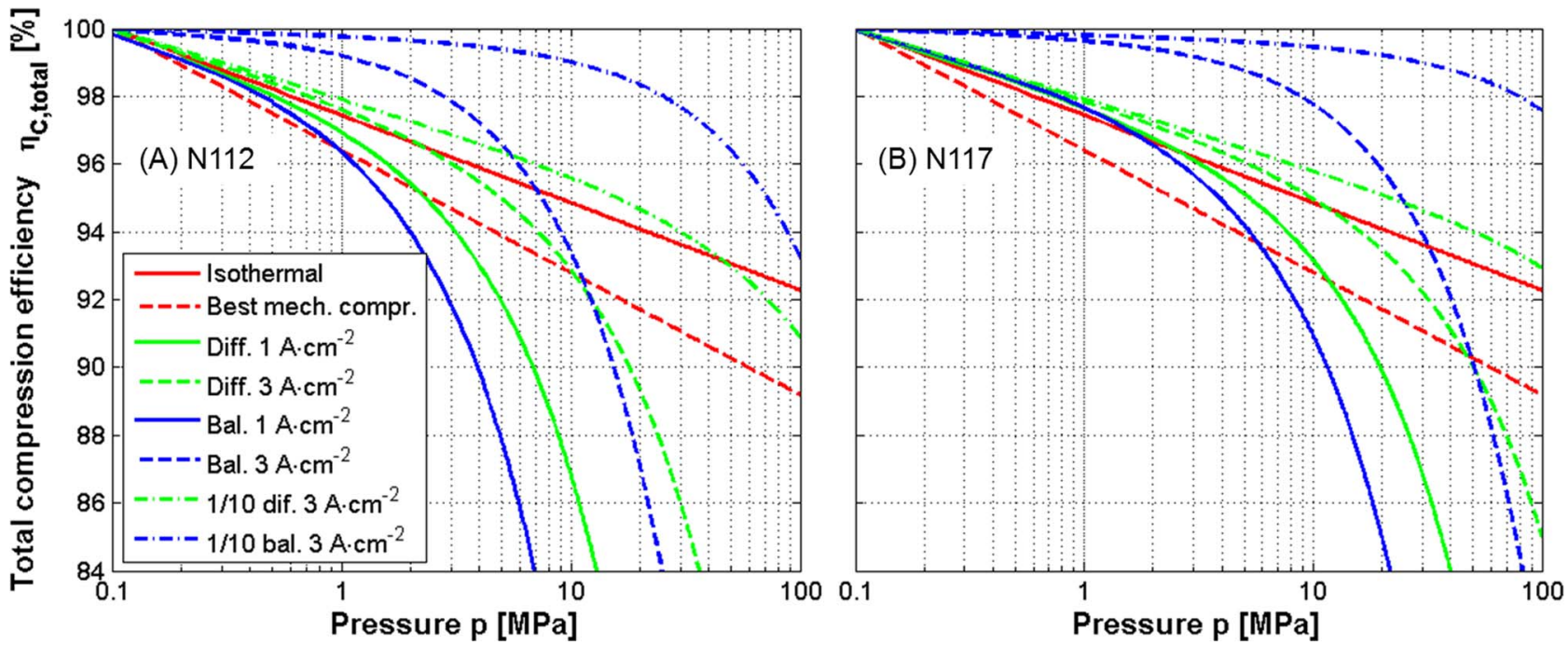

Figure 6. Total compression efficiencies for differential and balanced pressure PEWE using (A) Nafion 112 and (B) $\mathrm{Nafion} 117$ at $50^{\circ} \mathrm{C}$ for 1 and $3 \mathrm{~A} \cdot \mathrm{cm}{ }^{-2}$ as a function of the operating pressure. Hypothetic new membranes with $1 / 10$ of the Nafion permeability are added for comparison; the isothermal compression behavior at $50^{\circ} \mathrm{C}$ and best mechanical compression technology ${ }^{11}$ are also shown. The PEWE data is based on Figures 3 and $5 \mathrm{~B}$. 

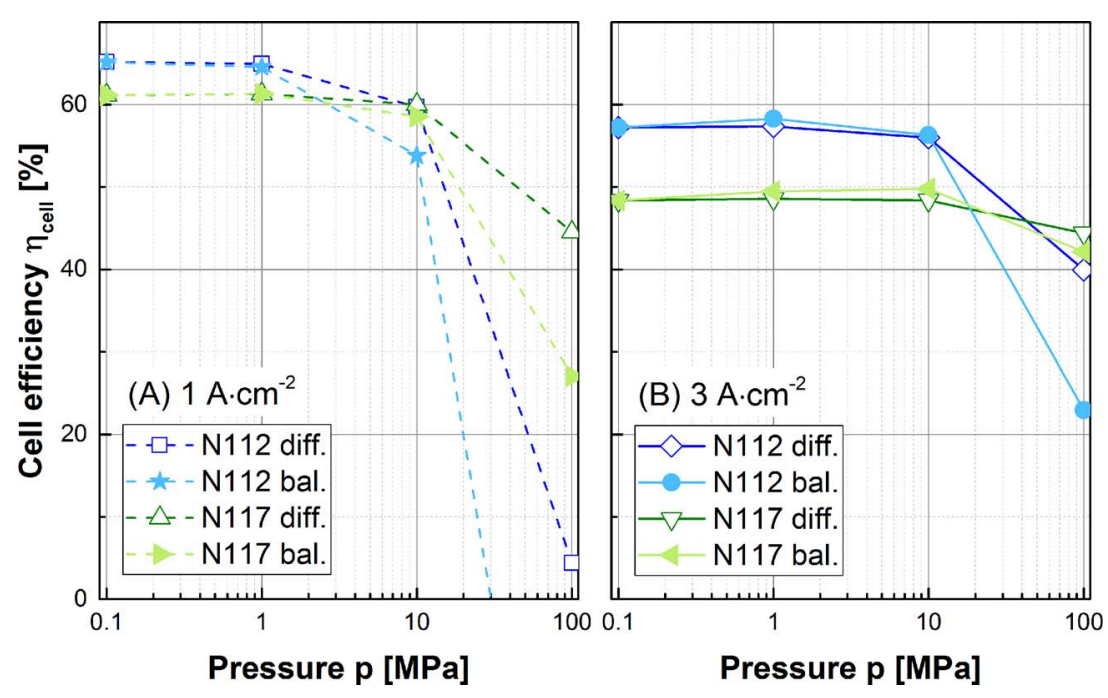

Figure 7. Cell efficiency (including all electrochemical and faradaic losses) according to Equation 8, normalized to $E_{\text {cell }}^{0}$ $=\mathrm{f}\left(\mathrm{p}_{\mathrm{H} 2}, \mathrm{~T}\right)$ or LHV of hydrogen, for differential and balanced pressure PEWE using Nafion 112 and Nafion 117 membranes at $50^{\circ} \mathrm{C}$ as a function of the operating pressure at (A) $1 \mathrm{~A} \cdot \mathrm{cm}^{-2}$ and (B) $3 \mathrm{~A} \cdot \mathrm{cm}^{-2}$.
- Cell efficiencies are almost constant up to $1 \mathrm{MPa}$ at $1 \mathrm{~A} \cdot \mathrm{cm}^{-2}$ and up to $10 \mathrm{MPa}$ at $3 \mathrm{~A} \cdot \mathrm{cm}^{-2}$. Further pressure increase reduces cell efficiencies, but less at high current densities (here $3 \mathrm{~A} \cdot \mathrm{cm}^{-2}$ ) due to the smaller influence of gas crossover and lower apparent compression effort for balanced pressure operation.

- At low current densities (here $1 \mathrm{~A} \cdot \mathrm{cm}^{-2}$ ) Nafion 112 has better cell efficiencies, with about $62 \%$ up to several MPa and about $60 \%$ at high current densities up to about $10 \mathrm{MPa}$, compared to Nafion 117 with about $60 \%$ and $50 \%$, respectively. However, at higher pressures the better gas barrier properties of Nafion 117 offset the higher ohmic overpotential.

Nevertheless, from an energetic point of view, the data show that low gas crossover membrane materials will be key for efficient electrochemical compression. For ultimate efficiency these materials would best be combined with the beneficial processes of the balanced pressure strategy where OER kinetic gains are (partly) compensating for the thermodynamic cell voltage increase due to pressurization. However, high-pressure oxygen (typically above $3 \mathrm{MPa}$ ) is a severe safety concern and difficult to implement in a technical process. Hence, it seems sensible to limit oxygen pressure. This will also be beneficial for the oxygen crossover losses, be it with conventional or future low gas permeation materials. For this novel pressure strategy we use the term "intermediate differential" pressure PEWE. Its characteristics with respect to hydrogen compression efficiency are discussed below.

Intermediate differential pressure PEWE.-With the OER kinetics following a logarithmic and the gas crossover following a linear pressure relation, there must be an optimum operating point minimizing the total compression losses by choosing a slightly increased anode and a considerably increased cathode pressure. Experiments have therefore been performed to better understand this novel pressure concept, where the anode is pressurized less than the cathode. In Figure 8A data with low anode pressures ( 1 and $2 \mathrm{MPa}$ ) and high cathode pressures ( 3 and $5 \mathrm{MPa}$ ) are shown. A relatively small anode pressure of $1 \mathrm{MPa}$ is sufficient to retain the voltage gains due to increased OER kinetics as no further decrease in cell voltage is observed with the oxygen pressure increase to $2 \mathrm{MPa}$, as shown in Figure $8 \mathrm{~B}$.

The experimental (1 / $5 \mathrm{MPa})$ data, are extrapolated to higher pressures with an isothermal compression behavior of $84 \%$ at $1 \mathrm{~A} \cdot \mathrm{cm}^{-2}$ and $24 \%$ at $3 \mathrm{~A} \cdot \mathrm{cm}^{-2}$ and compared to those from differential and balanced pressure in Figure 9. The extrapolated data show that at higher current densities the intermediate differential pressure concept is energetically more efficient than differential pressure operation due to a higher electrochemical compression efficiency, which is overcompensating the relatively small additional oxygen gas crossover losses. In particular at higher pressures the limited oxygen gas crossover losses for intermediate differential pressure are crucial for being more energetically efficient than all other pressure strategies and even better than mechanical compression up to almost $100 \mathrm{MPa}$ for Nafion 117.

Those experimental findings are rather counter-intuitive, because even if oxygen is considered as a by-product and only pressurized hydrogen is of interest, a $1 \mathrm{MPa}$ compression of oxygen is energetically beneficial. Furthermore operating and system investment costs (opex and capex) should be lower for intermediate differential than for balanced pressure operation due to lower safety requirements of the low pressurized oxygen and thus be similar to conventional differential pressure operation where the oxygen pressure is close to ambient pressure.

\section{Conclusions}

In this study, the cell voltage and gas crossover related losses due to electrochemical pressurization were investigated experimentally up to $5 \mathrm{MPa}$ and based on literature study up to $70 \mathrm{MPa}$ for differential and balanced pressure PEWE and EHCs. As expected from thermodynamics, differential pressure electrolysis and EHCs generally follow an isothermal compression behavior. In contrast, the apparent compression effort for balanced pressure electrolysis decreases with increasing current density due to improved OER kinetics. Part of this energetic advantage is offset by gas crossover losses roughly twice those of differential pressure operation.

The energetic analysis of the total hydrogen compression efficiency, combining electrochemical and faradaic losses, up to 100 MPa shows that differential pressure electrolysis is preferable to balanced pressure at low current densities $\left(\leq 1 \mathrm{~A} \cdot \mathrm{cm}^{-2}\right)$ due to lower gas crossover losses and similar compression behavior. However, at higher current densities the decreasing apparent compression effort of the balanced pressure PEWE compensates for the higher gas crossover losses resulting in higher total compression efficiencies.

Intermediate differential pressure electrolysis, with a slightly pressurized oxygen side and a higher pressure at the hydrogen side, combines the advantages of both pressure concepts retaining the low oxygen gas crossover losses of the differential pressure and the decreasing compression effort, at higher current densities of the balanced pressure operation. Based on the extrapolation of experimental data, the intermediate differential pressure strategy with cells having a membrane electrolyte with the gas permeation characteristics of Nafion 117 energetically outperform today's best mechanical compressors up to tens of MPa with similar compression losses at $100 \mathrm{MPa}$.

With respect to industrially relevant application, the intermediate differential pressure strategy respects the challenges and costs of compressed oxygen, which will be limited to close to those for conventional differential pressure PEWE with oxygen production at 

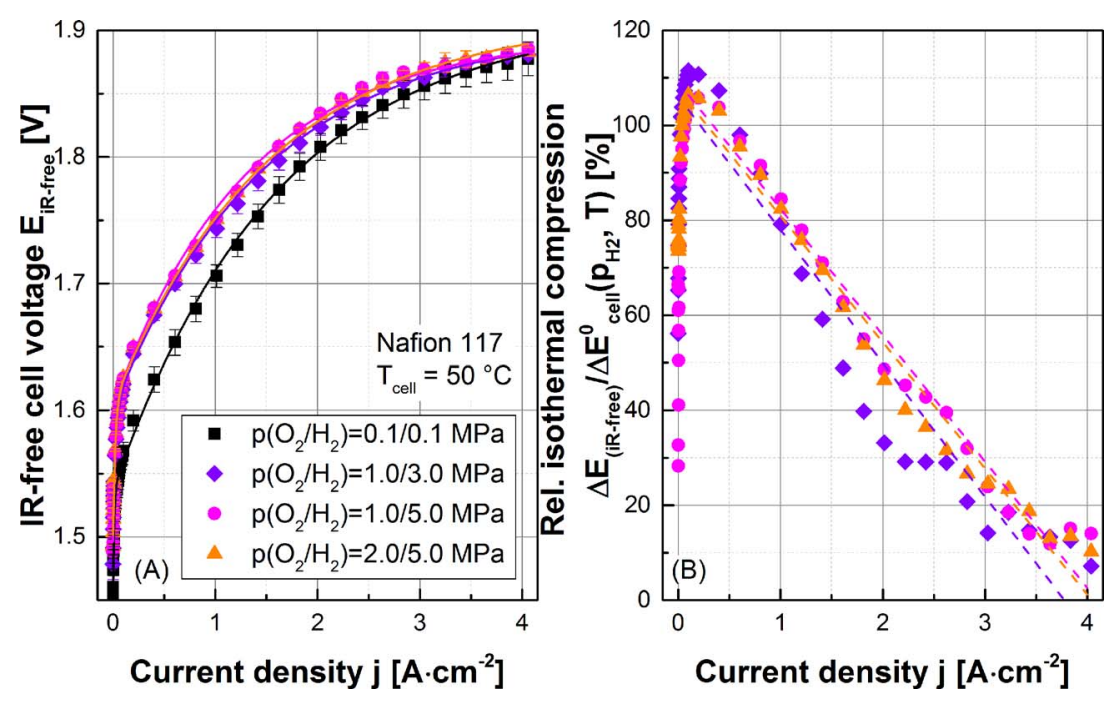

Figure 8. (A) intermediate differential pressure PEWE, iRfree $\mathrm{i} / \mathrm{E}$-curves at $50^{\circ} \mathrm{C}$ at indicated pressure levels; (B) ratio of the measured iR-free cell voltage difference between pressurized and ambient pressure operation $\left(\Delta E_{(\mathrm{iR} \text {-free })}\right)$ and the theoretical thermodynamic cell voltage increase $\left(\Delta E^{0}\right.$ cell $\left.\left(\mathrm{p}_{\mathrm{H} 2}, \mathrm{~T}\right)\right)$ considering only hydrogen compression, i.e. $100 \%$ represents an isothermal compression behavior according to Equation 1.
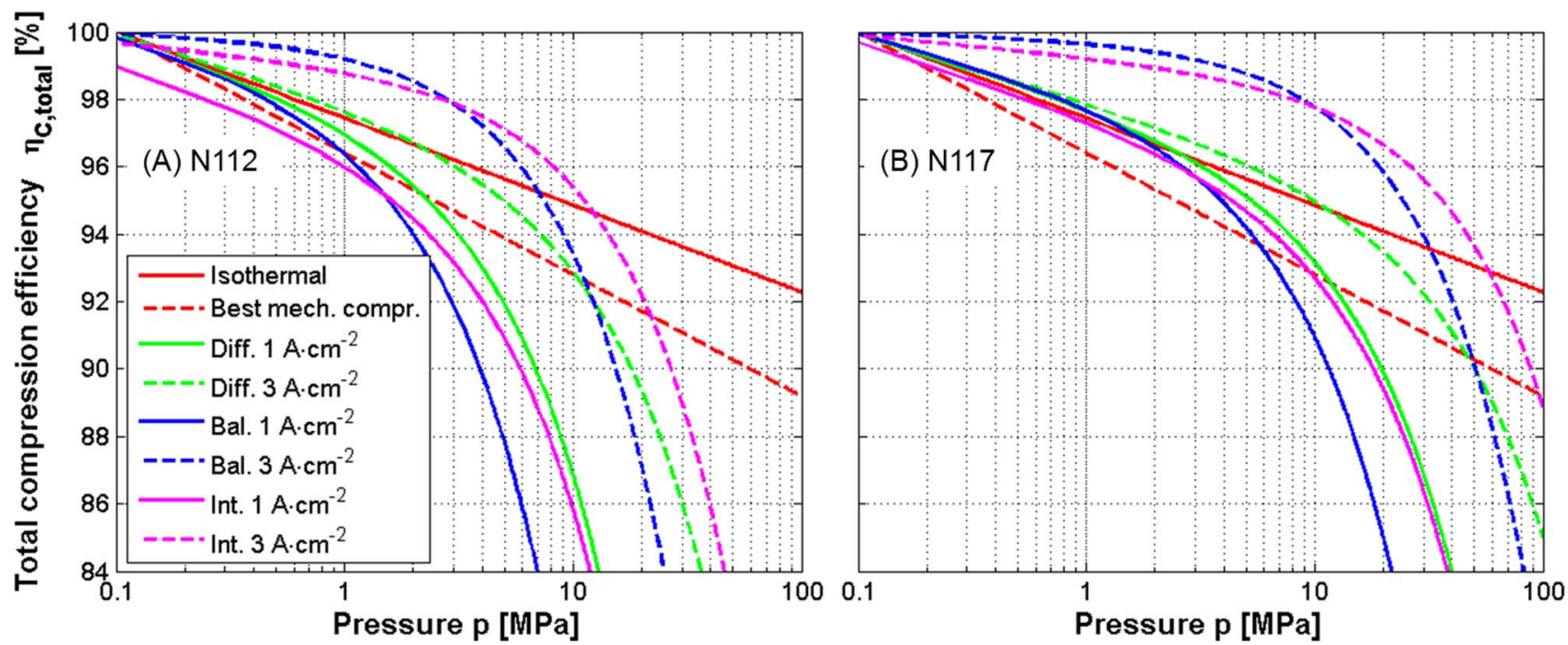

Figure 9. Total compression efficiencies for differential, balanced and intermediate differential pressure PEWE using (A) Nafion 112 and (B) Nafion 117 at $50^{\circ} \mathrm{C}$ for 1 and $3 \mathrm{~A} \cdot \mathrm{cm}^{-2}$ as a function of the operating pressure. For comparison the isothermal compression behavior at $50^{\circ} \mathrm{C}$ and best mechanical compression technology ${ }^{11}$ are added. The PEWE data is based on Figures 3, 5B and 8.

atmospheric pressure. If the technical risk, to have highest pressure hydrogen in the electrolyzer in close vicinity to pure oxygen, is considered too high, then a strategy with a combination of intermediate differential PEWE up to intermediate pressures of about $10 \mathrm{MPa}$ and final compression to highest pressures $(100 \mathrm{MPa})$ by EHCs seems a promising concept, with respect to both, energetic and safety properties.

\section{Acknowledgments}

Funding by the Swiss Federal Office of Energy (SFOE, under grant no. SI/500904-01), Belenos Clean Power Holding Ltd. and the Energy System Integration (ESI) platform at PSI, as well as technical support by Martin Ammann and Thomas Gloor (both PSI) are gratefully acknowledged. TJS thanks the Commission for Technology and Innovation Switzerland and the Swiss Competence Center for Energy Research Heat \& Electricity Storage.

\section{References}

1. http://ec.europa.eu/eurostat/web/energy/data/database, (accessed on 31.01.2017).

2. Erneuerbare Energien in Zahlen - Nationale und internationale Entwicklung im Jahr 2015, in, Bundesministerium für Wirtschaft und Energie (BMWi) (2016).

3. C. J. Barnhart, M. Dale, A. R. Brandt, and S. M. Benson, Energy \& Environmental Science, 6, 2804 (2013)
4. Monitoringbericht 2016, in, G. Bundesnetzagentur für Elektrizität, Telekommunikation, Post und Eisenbahnen; Bundeskartellamt Editor, Bundesnetzagentur für Elektrizität, Gas,Telekommunikation, Post und Eisenbahnen; Bundeskartellamt (2016).

5. T. Smolinka, E. T. Ojong, and J. Garche, in Electrochemical Energy Storage for Renewable Sources and Grid Balancing, P. T. Moseley and J. Garche Editors, p. 103 (2015).

6. https://energy.gov/eere/fuelcells/doe-technical-targets-hydrogen-production-electrolysis, (accessed on 10.03.2017).

7. J. Alkire, Technology Validation Program Area - Plenary Presentation, U. S. Department of Energy, 2017 Annual Merit Review and Peer Evaluation Meeting (2017).

8. http://www.energiepark-mainz.de/, (accessed on 10.03.2017).

9. M. Kopp, D. Coleman, C. Stiller, K. Scheffer, J. Aichinger, and B. Scheppat, International Journal of Hydrogen Energy, 42(19) (2017).

10. S. Metz, Fuel Cells Bulletin, 2014, 12 (2014).

11. M. Stefan, in, 20th World Hydrogen Energy Conference (WHEC), KDJ Convention Center Gwangju, South Korea (2014).

12. H. Ishikawa, E. Haryu, N. Kawasaki, and H. Daimon, Honda R\&D Technical Review, 28 (2016).

13. P. J. Bouwman, J. Konink, D. Semerel, L. Raymakers, M. Koeman, W. Dalhuijsen, E. Milacic, and M. Mulder, ECS Transactions, 64, 1009 (2014).

14. D. G. Bessarabov, H. Wang, H. Li, and N. Zhao, PEM Electrolysis for Hydrogen Production: Principles and Applications, CRC Press, Boca Raton, FL (USA) (2015).

15. L. Bertuccioli, A. Chan, D. Hart, F. Lehner, B. Madden, and E. Standen, Study on Development of Water Electrolysis in the EU by E4tech S'arl with Element Energy Ltd for the Fuel Cells and Hydrogen Joint Undertaking, in (2014).

16. M. Carmo, D. L. Fritz, J. Mergel, and D. Stolten, International Journal of Hydrogen Energy, 38, 4901 (2013). 
17. C. K. Mittelsteadt and J. A. Staser, in Polymer Science: A Comprehensive Reference, p. 849 (2012)

18. B. Bensmann, R. Hanke-Rauschenbach, G. Müller-Syring, M. Henel, and K. Sundmacher, Applied Energy, 167, 107 (2016).

19. M. Suermann, K. Takanohashi, A. Lamibrac, T. J. Schmidt, and F. N. Büchi, Journal of The Electrochemical Society, 164, F973 (2017).

20. M. Suermann, A. Pătru, T. J. Schmidt, and F. N. Büchi, International Journal of Hydrogen Energy, 42, 12076 (2017).

21. M. Suermann, T. J. Schmidt, and F. N. Büchi, Electrochimica Acta, 211, 989 (2016)

22. I. Barin and G. Platzki, Thermochemical Data of Pure Substances, p. 795, VCH Verlagsgesellschaft mbH, Weinheim (1995).

23. H. Ito, T. Maeda, A. Nakano, and H. Takenaka, International Journal of Hydrogen Energy, 36, 10527 (2011).

24. R. Wiebe and V. L. Gaddy, J. Am. Chem. Soc., 56, 76 (1934).

25. D. Tromans, Hydrometallurgy, 48, 327 (1998).

26. S. A. Grigoriev, M. M. Khaliullin, N. V. Kuleshov, and V. N. Fateev, Russian Journal of Electrochemistry, 37, 819 (2001).

27. K. E. Ayers, E. B. Anderson, C. B. Capuano, B. D. Carter, L. T. Dalton, G. Hanlon, J. Manco, and M. Niedzwiecki, ECS Transactions, 33, 3 (2010).

28. M. Bernt and H. A. Gasteiger, Journal of The Electrochemical Society, 163, F3179 (2016).

29. S. A. Grigoriev, V. I. Porembskiy, S. V. Korobtsev, V. N. Fateev, F. Auprêtre, and P. Millet, International Journal of Hydrogen Energy, 36, 2721 (2011).
30. Siemens, Bayern-Innovativ-Kongress: Energiespeicher - Technologien für die zukünftige Stromversorgung, Nuremberg, Germany (2011).

31. NIST Reference Fluid Thermodynamic and Transport Properties Database (REFPROP): Version 8.0, (accessed on 06.04.2017).

32. M. W. Melaina, O. Antonia, and M. Penev, Blending Hydrogen into Natural Gas Pipeline Networks: A Review of Key Issues, in, NREL (2013).

33. J. Durst, A. Siebel, C. Simon, F. Hasché, J. Herranz, and H. A. Gasteiger, Energy \& Environmental Science, 7, 2255 (2014).

34. S. Shi, A. Z. Weber, and A. Kusoglu, Journal of Membrane Science, 516, 123 (2016).

35. S. A. Grigoriev, I. G. Shtatniy, P. Millet, V. I. Porembsky, and V. N. Fateev, International Journal of Hydrogen Energy, 36, 4148 (2011).

36. R. Ströbel, M. Oszcipok, M. Fasil, B. Rohland, L. Jörissen, and J. Garche, Journal of Power Sources, 105, 208 (2002).

37. C. Casati, P. Longhi, L. Zanderighi, and F. Bianchi, Journal of Power Sources, 180, 103 (2008).

38. F. Barbir, Solar Energy, 78, 661 (2005).

39. M. Schalenbach, T. Hoefner, P. Paciok, M. Carmo, W. Lueke, and D. Stolten, The Journal of Physical Chemistry C, 119, 25145 (2015).

40. M. Schalenbach and D. Stolten, Electrochimica Acta, 156, 321 (2015).

41. T. Sakai, H. Takenaka, N. Wakabayashi, Y. Kawami, and E. Torikai, J. Electrochemical Soc., 132, 1328 (1985).

42. U. Babic, M. Suermann, F. N. Büchi, L. Gubler, and T. J. Schmidt, Journal of The Electrochemical Society, 164, F387 (2017). 